\title{
Prevalence and risk factors of contralateral extraprostatic extension in men undergoing radical prostatectomy for unilateral disease at biopsy: A global multi-institutional experience
}

\author{
Marc Bienz;, Pierre-Alain Hueber, MD, PhD; ${ }^{*}$ Vincent Trudeau, MD; ${ }^{*}$ Abdullah M. Alenizi, MD; \\ Roger Valdivieso, MD; Modar Alom, MD; Mevlana Derya Balbay, MD; ${ }_{;}^{\dagger}$ Abdullah Erdem Canda, MD;* \\ Vladimir Mouraviev, MD, PhD; ${ }^{\dagger}$ David M. Albala, MD; ${ }^{\dagger}$ Assaad El-Hakim, MD, FRCSC, ${ }^{\ddagger}$ Quoc-Dien Trinh, MD, \\ FRCSC, ${ }^{ \pm}$Mathieu Latour, MD,* Fred Saad, MD, FRCSC,; Kevin C. Zorn, MD, FACS, FRCSC*
}

\#Faculty of Medicine, University of Montreal, Montreal, QC; * Department of Urology, University of Montreal Hospital Centre (CHUM), Hôpital St. Luc, Montreal, QC; ${ }^{\dagger}$ Associated Medical Professionals of New York, New York, NY; §Memorial Sisli Hospital, Department of Urology, Istanbul, Turkey; ${ }^{*}$ Yildirim Beyazit University, School of Medicine, Ankara Ataturk Training and Research Hospital, Department of Urology, Ankara, Turkey; ${ }^{E}$ Department of Urology, Sacré-Coeur Hospital, Montreal, QC; ${ }^{ \pm}$Division of Urologic Surgery and Center for Surgery and Public Health, Brigham and Women's Hospital/Dana-Farber Cancer Institute, Harvard Medical School, Boston, MA

Cite as: Can Urol Assoc J 2015;9(7-8):E434-8. http://dx.doi.org/10.5489/cuaj.2786 Published online July 17, 2015.

\section{Abstract}

Introduction: We assessed the incidence of contralateral prostate cancer (cPCa), contralateral EPE (cEPE) and contralateral positive surgical margins (CPSM) in patients diagnosed preoperatively with unilateral prostate cancer and evaluated risk factors predictive of contralateral disease extension.

Methods: The occurrence of CPCa, cEPE and cPSM and the sidespecific nerve-sparing technique performed were collected postoperatively from 327 men diagnosed with unilateral prostate cancer at biopsy. Parameters, such as the localization, proportion, and percentage of cancer in positive cores, were prospectively collected. Results: Overall, $50.5 \%$ of patients had bilateral disease, and were at higher risk when associated with a positive biopsy core at the apex $(p=0.016)$. The overall incidence of ipsilateral EPE and cEPE were $21.4 \%$ and $3.4 \%$, respectively $(p<0.001)$. Compared to $\mathrm{CPCa}$, ipsilateral disease was at an almost 4-fold higher risk of extending out of the prostate $(p<0.001)$. None of the criteria tested were identified as useful predictors for cEPE. The low incidence of cEPE in our cohort could limit our ability to detect significance. The overall incidence of ipsilateral PSM and cPSM were $15.3 \%$ and $5.8 \%$, respectively $(p<0.001)$. More aggressive nerve-sparing was not associated with a higher incidence of PSM. Prostate sides selected for more aggressive nerve-sparing were associated with younger patients $(p<0.001)$, a smaller prostate $(p=0.006)$, and a lower percentage of cancer in biopsy material ( $p=0.008)$.

Conclusion: Although the risk of $\mathrm{CPCa}$ is high in patients diagnosed with unilateral prostate cancer at biopsy, the risk of cEPE and cPSM is low, yet not insignificant. Contralateral aggressive nervesparing should be used with caution and should not compromise oncological outcome.

\section{Introduction}

Prostate cancer is the most prevalent cancer among men in North America. ${ }^{1}$ The stage migration toward low-risk disease and in consequence prolonged survival of patients has shifted our attention towards the preservation of quality of life in men treated for prostate cancer. Current techniques used for radical prostatectomy (RP) cause urinary and erectile dysfunction in a significant proportion of patients, with $2 \%$ to $20 \%$ not recovering full continence ${ }^{2}$ and about $50 \%$ not recovering sexual function within 1 year. ${ }^{3}$ Due to the proximity of the nerve bundles to the prostate gland, a technical and conceptual challenge resides in striking a balance between the preservation of the neurovascular bundle (i.e., nerve-sparing technique) and the risk of positive surgical margins (PSM). In a recent meta-analysis, the mean incidence of PSM was $15 \% .{ }^{4}$ While the decision to perform nerve sparing is surgeon-dependent, several models have been developed to help identify good candidates for such procedures. As described by Ohori and colleagues, prostatic-specific antigen (PSA) levels, digital rectal exam findings, and biopsy Gleason score may predict the risk of side-specific extra-prostatic extension (EPE). ${ }^{5,6}$ Similarly, PSA, low prostate volume, a biopsy Gleason score of 7 , and interfascial neurovascular bundle dissection were described as side-specific predictors of PSM by Secin and colleagues. ${ }^{7}$

There is little data on contralateral disease extension in unilateral prostate cancer diagnosed at biopsy. Few studies have focused on the reliability of unilaterally positive biopsies to adequately predict the presence of less invasive disease to the contralateral side. ${ }^{8-10}$ On the basis of these considerations, we assessed the incidence of bilateral disease, contralateral EPE (cEPE), and contralateral positive surgical 
margins (CPSM) in patients diagnosed preoperatively with unilateral disease, and evaluated risk factors predictive of contralateral disease extension.

\section{Methods}

\section{Cohort}

Following institutional review board approval, we identified 327 patients who were diagnosed with unilateral prostate cancer at biopsy. All patients underwent robot-assisted radical prostatectomy (RARP) between 2010 and 2013 performed in 5 sites in Canada, the United States, and Turkey. Only patients who underwent the entire procedure in a standard fashion were included in the study. No men had prior pelvic radiation or neoadjuvant therapy. Patients underwent a 12-core biopsy scheme guided by bi-dimensional transrectal ultrasonography (TRUS). All centress perform at least 800 TRUS-guided biopsies yearly. Baseline parameters, localization of positive cores, proportion of positive cores, percentage of cancer in biopsy material, Gleason Score, and clinical tumour stage were recorded in a standardized data collection sheet.

\section{Surgical technique and specimen preparation}

Surgeons had a minimum fellowship experience of 200 cases. RARP was performed in a standard fashion using the robotic da Vinci system (Intuitive Surgical Inc., CA). ${ }^{11-13}$ Nerve preservation was performed according to the surgeon's preference and classified according to the extent of nerve sparing as interfascial (IF-NS), extrafascial/partial (EFNS), and wide extrafascial resection (WEFR).

The surgical specimens were processed according to modified Stanford protocol ${ }^{14}$ and microscopically examined by an uro-pathologist. ${ }^{15}$ EPE was defined as cancerous tissue found on the outside of the limit of healthy prostatic tissue and associated with the stage pT3. PSM was defined as tumour cells present at the inked margin of the specimen.

The localization of the positive biopsy cores (available for $24 \%$ of patients), EPE (available for $57 \%$ of patients) and PSM (available for $37 \%$ of patients) were categorized as the apex, the mid region, and the base of the prostate. Data did not allow more precise substratification for the anterior/posterior regions of the apex and of the base, and for the anterior/anterolateral/posterolateral/posterior regions of the mid-gland. ${ }^{16,17}$

\section{Data analysis}

Data were prospectively collected and retrospectively analyzed. All tests were two-sided and a $p$ value of 0.05 was deemed statistically significant. The IBM SPSS Statistics package (IBM Corporation, version 21, Armonk, NY) was used for analysis. Distribution was evaluated using the Shapiro-Wilk's test. Data were summarized using descriptive statistics, and central tendency was measured with the median followed by the first and third quartiles $(25 \%-75 \%)$. Continuous variables were analyzed with the Mann Whitney $U$ test. The chi-square test and the Fisher's exact test were used with categorical variables. Lastly, a univariate binomial logistic model was used to evaluate risk. Multivariate models encompassed all variables with a $p<0.3$.

\section{Results}

\section{Characteristics of the study population}

Our cohort is composed of 327 men diagnosed with unilateral prostate cancer at biopsy. We tallied patient baseline characteristics (Table 1). On the ipsilateral side to the positive biopsy, $66.4 \%$ of patients underwent IF-NS, $27.5 \%$ EF-NS, and $6.1 \%$ did not undergo a nerve-sparing procedure. On the contralateral side, $81.5 \%$ of patients underwent IF-NS, $17.3 \%$ EF-NS, and $1.2 \%$ did not undergo nerve-sparing procedure. A significantly higher proportion of IF-NS was performed on the contralateral side of the prostate compared to the ipsilateral side $(p<0.001)$.

\begin{tabular}{|c|c|c|}
\hline \multicolumn{2}{|l|}{ Parameters } & Cohort \\
\hline \multicolumn{2}{|l|}{ Cohort size } & 327 \\
\hline \multicolumn{2}{|l|}{ Age, years } & $61.0(55.0-65.0)$ \\
\hline \multirow[t]{2}{*}{$\mathrm{BMI}, \mathrm{kg} / \mathrm{cm}^{2}$} & & $26.9(25.0-29.4)$ \\
\hline & Caucasian & $92.1(301)$ \\
\hline \multirow[t]{3}{*}{ Race, \% } & Black & $2.1(7)$ \\
\hline & Other & $5.8(19)$ \\
\hline & $\leq 6$ & $41.0(134)$ \\
\hline \multirow[t]{2}{*}{ Gleason score, \% } & 7 & $52.3(171)$ \\
\hline & $\geq 8$ & $6.7(22)$ \\
\hline \multicolumn{2}{|l|}{ TRUS prostate size, cc } & $38(30-50)$ \\
\hline \multicolumn{2}{|l|}{ Baseline PSA, ng/mL } & $5.3(4.1-7.1)$ \\
\hline \multicolumn{2}{|c|}{ Proportion of positive cores, $\%$} & $20.0(16.7-33.3)$ \\
\hline \multicolumn{2}{|c|}{ Percentage of cancer in biopsy material, \% } & $30.0(15.0-64.0)$ \\
\hline \multirow{4}{*}{ cStage (\%) } & cT1c & $76.0(240)$ \\
\hline & cT2a & $18.0(56)$ \\
\hline & $\mathrm{cT} 2 \mathrm{~b}$ & $5.7(18)$ \\
\hline & сТ3a & $0.3(1)$ \\
\hline \multirow{3}{*}{ D'Amico risk categories } & Low risk & $47(154)$ \\
\hline & Intermediate risk & $46(151)$ \\
\hline & High risk & $7(22)$ \\
\hline
\end{tabular}

Data presented as a median (Q1-Q3) or \% (n). BMI: body mass index; TRUS: transrectal ultrasound; PSA: prostate-specific antigen; cStage: clinical stage. 
Bienz et al.

\begin{tabular}{|c|c|c|c|c|}
\hline Localization & Ipsilateral EPE & Contralateral EPE & Ipsilateral PSM & Contralateral PSM \\
\hline Apex & $14.6(6 / 41)$ & $0.0(0 / 5)$ & $43.5(10 / 23)$ & $60.0(6 / 10)$ \\
\hline Mid & $58.5(24 / 41)$ & $40.0(2 / 5)$ & $39.1(9 / 23)$ & $30.0(3 / 10)$ \\
\hline Base & $39.0(16 / 41)$ & $60.0(3 / 5)$ & $43.5(10 / 23)$ & $50.0(5 / 10)$ \\
\hline
\end{tabular}

Data presented as a $\%$ (n). Missing data for iEPE $n=29$, cEPE $n=6$, iPSM $n=27$, cPSM $n=9$. EPE: extra-prostatic extension; PSM: positive surgical margins.

\section{Disease extension}

Overall 50.5\% (165/327) of patients had bilateral disease according to the postoperative pathological report. On the ipsilateral side to the positive biopsy, $21.4 \%$ (70/327) had EPE. On the contralateral side, the overall proportion of cEPE was significantly lower than on the ipsilateral side with an incidence of $3.4 \%(11 / 327)(p<0.001)$. In fact, using a binomial logistic regression model, our results show that the risk of ipsilateral disease extending out of the prostate is almost 4 times higher than the risk of contralateral disease extending out of the prostate (odds ratio [OR] 3.813, 95\% confidence interval [CI] 1.958-7.425, $p<0.001$ ). The localization of ipsilateral EPE (iEPE) and cEPE is reported in Table 2.

In a univariate model, preoperative predictive parameters of increased risk for contralateral prostate cancer ( $\mathrm{CPCa}$ ) and cEPE were also evaluated (Table 3). For predictors of CPCa, the subsequent multivariate analysis showed that a positive biopsy at the apex was associated with a 4-fold higher risk of CPCa in patients diagnosed with unilateral prostate cancer at biopsy (OR 4.565, 95\% Cl 1.333-15.630, $p=0.016$ ).
None of all parameters tested to evaluate the risk of cEPE were significant (Table 3).

\section{Positive surgical margins}

Overall, the incidence of ipsilateral PSM (iPSM) in our cohort was of $15.3 \%$ (50/327). The side of the prostate with iEPE was associated with a significant 4-fold higher risk of being associated with iPSM compared to those without iEPE (OR 4.356, 95\% Cl 2.290-8.287, $p<0.001$ ). On the contralateral side of the positive biopsy, the cohort's overall incidence of cPSM was 5.8\% (19/327) and was significantly lower than the incidence of iPSM $(p<0.001)$. cEPE was associated with an almost 7-fold higher risk of cPSM compared to prostate sides without cEPE (OR 6.844, 95\% Cl 1.656-28.289, $p=0.008$ ) (Fig. 1). The localization of PSM is presented in Table 2.

Lastly, less aggressive nerve sparing (WEFR or EF-NS) was not associated with significantly different rates of PSM on the ipsilateral and contralateral sides, with rates of $17.3 \%$ $(14 / 81)$ and $27.6 \%(8 / 29)$, respectively $(p=0.234)$. With the IF-NS technique, the rates of iPSM tended to be higher

Table 3. Univariate analysis of potential predicting factors of cPCa and cEPE

\begin{tabular}{|c|c|c|c|c|c|c|c|c|c|}
\hline \multicolumn{2}{|c|}{ Univariate analysis } & $\begin{array}{l}\text { Unilateral } \\
\text { PCa }\end{array}$ & Bilateral PCa & OR (95\% Cl) & $p$ value & No cEPE & cEPE & OR (95\%Cl) & $p$ value \\
\hline \multicolumn{2}{|l|}{ Age, years } & $\begin{array}{c}61.0 \\
(56.0-65.0)\end{array}$ & $\begin{array}{c}60.0 \\
(54.0-65.0)\end{array}$ & $\begin{array}{c}0.969 \\
(0.943-0.996)\end{array}$ & 0.025 & $\begin{array}{c}61.0 \\
(55.0-65.0)\end{array}$ & $\begin{array}{c}59.0 \\
(52.0-64.0)\end{array}$ & $\begin{array}{c}0.992 \\
(0.927-1.060)\end{array}$ & 0.806 \\
\hline \multicolumn{2}{|l|}{$\mathrm{BMI}, \mathrm{kg} / \mathrm{cm}^{2}$} & $\begin{array}{c}26.6 \\
(25.0-29.5)\end{array}$ & $\begin{array}{c}27.2 \\
(24.9-29.3)\end{array}$ & $\begin{array}{c}1.021 \\
(0.966-1.079)\end{array}$ & 0.456 & $\begin{array}{c}26.9 \\
(25.1-29.5)\end{array}$ & $\begin{array}{c}27.1 \\
(23.6-28.5)\end{array}$ & $\begin{array}{c}0.931 \\
(0.814-1.065)\end{array}$ & 0.294 \\
\hline \multicolumn{2}{|c|}{ Baseline PSA, ng/mL } & $\begin{array}{c}5.3 \\
(4.17-7.01)\end{array}$ & $\begin{array}{c}5.3 \\
(4.08-7.34)\end{array}$ & $\begin{array}{c}1.013 \\
(0.957-1.072)\end{array}$ & 0.653 & $\begin{array}{c}5.3 \\
(4.1-7.1)\end{array}$ & $\begin{array}{c}6.7 \\
(4.3-8.1)\end{array}$ & $\begin{array}{c}1.019 \\
(0.882-1.178)\end{array}$ & 0.794 \\
\hline \multicolumn{2}{|c|}{$\begin{array}{l}\text { Proportion of positive } \\
\text { cores, } \%\end{array}$} & $\begin{array}{c}20.0 \\
(16.7-33.3)\end{array}$ & $\begin{array}{c}16.7 \\
(8.3-33.3)\end{array}$ & $\begin{array}{c}1.000 \\
(0.984-1.016)\end{array}$ & 0.986 & $\begin{array}{c}20.0 \\
(16.7-33.3)\end{array}$ & $\begin{array}{c}33.3 \\
(16.7-43.7)\end{array}$ & $\begin{array}{c}1.029 \\
(0.989-1.072)\end{array}$ & 0.161 \\
\hline \multicolumn{2}{|c|}{$\begin{array}{l}\text { Percentage of cancer } \\
\text { in biopsy material, \% }\end{array}$} & $\begin{array}{c}30 \\
(18-61)\end{array}$ & $\begin{array}{c}25 \\
(10-70)\end{array}$ & $\begin{array}{c}0.999 \\
(0.992-1.006)\end{array}$ & 0.795 & $\begin{array}{c}30 \\
(15-60)\end{array}$ & $\begin{array}{c}65 \\
(20-80)\end{array}$ & $\begin{array}{c}1.014 \\
(0.994-1.034)\end{array}$ & 0.166 \\
\hline \multicolumn{2}{|c|}{$\begin{array}{l}\text { Biopsy Gleason score } \\
\geq 8, \%\end{array}$} & $\begin{array}{c}6.2 \\
(10 / 162)\end{array}$ & $\begin{array}{c}7.3 \\
(12 / 165)\end{array}$ & $\begin{array}{c}1.192 \\
(0.500-2.842)\end{array}$ & 0.692 & $\begin{array}{c}7.0 \\
(22 / 316)\end{array}$ & $\begin{array}{c}0.0 \\
(0 / 11)\end{array}$ & - & 0.998 \\
\hline \multicolumn{2}{|c|}{ TRUS prostate size, cc } & $\begin{array}{c}40 \\
(30-51)\end{array}$ & $\begin{array}{c}60 \\
(54-65)\end{array}$ & $\begin{array}{c}0.992 \\
(0.978-1.005)\end{array}$ & 0.227 & $\begin{array}{c}38 \\
(30-50)\end{array}$ & $\begin{array}{c}38 \\
(28-47.5)\end{array}$ & $\begin{array}{c}0.995 \\
(0.961-1.031)\end{array}$ & 0.778 \\
\hline \multirow{3}{*}{$\begin{array}{l}\text { Biopsy } \\
\text { localization, } \\
\%\end{array}$} & Apex & $\begin{array}{c}33.3 \\
(11 / 33)\end{array}$ & $\begin{array}{c}62.2 \\
(28 / 45)\end{array}$ & $\begin{array}{c}3.294 \\
(1.284-8.448)\end{array}$ & 0.013 & $\begin{array}{c}47.1 \\
(33 / 70)\end{array}$ & $\begin{array}{l}75.0 \\
(6 / 8)\end{array}$ & $\begin{array}{c}3.364 \\
(0.635-17.827)\end{array}$ & 0.154 \\
\hline & Mid & $\begin{array}{c}78.8 \\
(26 / 33)\end{array}$ & $\begin{array}{c}73.3 \\
(33 / 45)\end{array}$ & $\begin{array}{c}0.740 \\
(0.255-2.147)\end{array}$ & 0.580 & $\begin{array}{c}75.7 \\
(53 / 70)\end{array}$ & $\begin{array}{l}75.0 \\
(6 / 8)\end{array}$ & $\begin{array}{c}0.962 \\
(0.177-5.220)\end{array}$ & 0.964 \\
\hline & Base & $\begin{array}{c}54.5 \\
(18 / 33)\end{array}$ & $\begin{array}{c}62.2 \\
(28 / 45)\end{array}$ & $\begin{array}{c}1.373 \\
(0.551-3.418)\end{array}$ & 0.496 & $\begin{array}{c}60.0 \\
(42 / 70)\end{array}$ & $\begin{array}{l}50.0 \\
(4 / 8)\end{array}$ & $\begin{array}{c}0.667 \\
(0.154-2.888)\end{array}$ & 0.588 \\
\hline
\end{tabular}

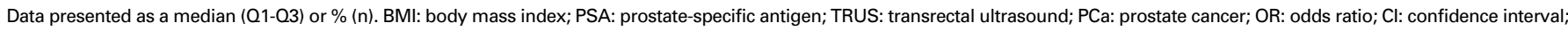
cEPE: contralateral extra-prostatic extension. 


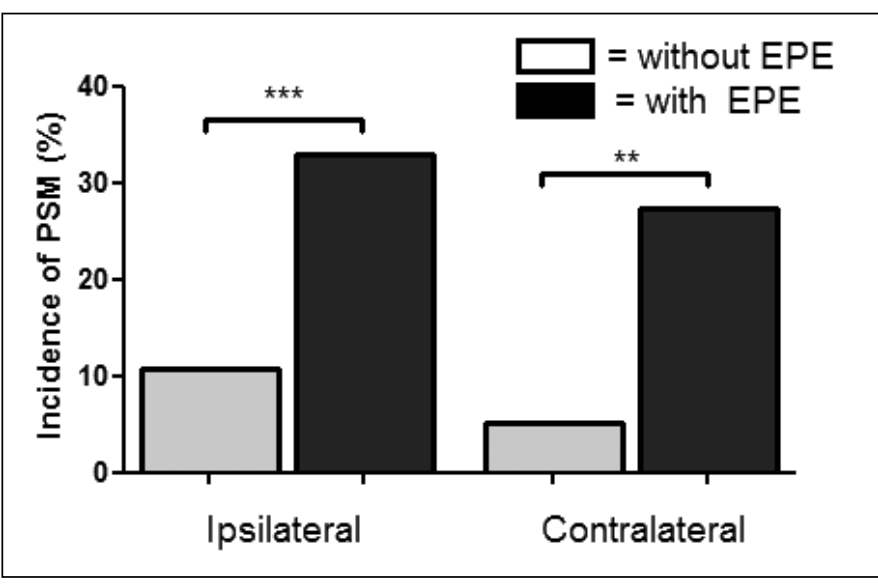

Fig. 1. Rates of positive surgical margins (PSM) without extra-prostatic extension (EPE) (white) and with EPE (black) on the ipsilateral and contralateral side of the positive biopsies. ${ }^{*} p<0.05,{ }^{* *} p<0.01,{ }^{* * *} p<0.001$.

at $17.0 \%(27 / 159)$ compared to rates of cPSM with $9.3 \%$ (9/97) $(p=0.085)$. Interestingly, rates associated with IF-NS were similar to those associated with WEFR/EF-NS on the ipsilateral side $(17.0 \%$ vs. $17.4 \%, p=0.953)$ and were significantly lower when associated with IF-NS on the contralateral side $(27.6 \%$ vs. $9.3 \%, p=0.011)$. To understand why more aggressive nerve sparing did not result in more PSM, a multivariate analysis was performed and showed that prostate sides dissected with IF-NS were associated with younger patients $(p<0.001)$, a smaller prostate size $(p=0.006)$, and a lower percentage of cancer in biopsy material $(p=0.008)$.

\section{Discussion}

In unilaterally positive biopsies of the prostate, a more aggressive contralateral nerve-sparing approach is attractive. In fact, unilateral nerve sparing may help preserve the neurovascular bundle on a side less likely to be affected by prostate cancer. ${ }^{18}$ However, few studies have investigated the incidence and extent of contralateral disease extension in such cases. In regards to disease extension within the contralateral lobe, a laparoscopic series by Frota and colleagues showed that unilaterally positive biopsies correlated weakly with both prostate cancer and PSM localization. ${ }^{19}$ They reported that $79 \%$ and $82 \%$ of prostates in which biopsies were only positive on the right and left lobe had bilateral disease, respectively. Similarly, a study by Gallina and colleagues of 321 consecutive low-risk patients with unilateral disease at biopsy showed that $60.7 \%$ had bilateral disease following RP. ${ }^{20}$ In our cohort, the incidence of bilateral disease at resection was lower (50.5\%). The Gleason score, clinical stage, PSA, and number of biopsy cores were not markedly different compared to the studies from Frota and colleagues ${ }^{19}$ and Gallina and colleagues. ${ }^{20}$ This difference could be explained by our multi-institutionnal cohort.
A series by Sfoungaristos and colleagues identified PSA density and percentage of cancer in biopsy material as independent predicting factors of bilateral disease. ${ }^{10}$ In our report, a positive biopsy at the apex was a predictor of contralateral disease. In fact, the apex represents a much smaller proportion of the gland than the mid and base regions. The disease will likely spread to the contralateral side. While this hypothesis warrants further investigation, this could be used as a red flag to exert additional care during the dissection of the apex. In fact, the highest rate of PSM was found at the apex both on the ipsilateral (43.5\%) and contralateral $(60.0 \%)$ sides. A study from Smith and colleagues reported similar results with the most common localization for PSM after RARP at the apex (52\%). ${ }^{21}$ The high incidence of PSM at the apex may be due to the technical difficulty associated with its dissection. As described by Tewari and colleagues the prostatic apex is the "Achilles heel" of prostate cancer surgery. This may be explained by the challenge of differentiating the prostate from the dorsal venous complex and the sphincter of the urethra. ${ }^{22}$

The overall incidence of cPSM was low (6\%). PSM may occur following a surgical incision through the prostate or through preexisting EPE. Prostates with cEPE were associated with a high incidence of CPSM (27.3\%) and a near 7-fold higher risk of PSM compared to those without EPE. In fact, when comparing rates of PSM in lobes with no EPE, we found similar rates of capsular incisions with $10.7 \%$ on the ipsilateral side and in patients with contralateral disease, and $10.9 \%$ on the contralateral side. These results compare favourably with rates obtained by Kwak and colleagues. ${ }^{23}$ In their cohort, they reported $15.6 \%$ of PSM for organ-confined disease. Although contralateral disease was common, it was associated with a low risk of extension beyond the contralateral capsule. Specifically, the overall incidence of cEPE was low (3.4\%). The localization of EPE was mainly in the mid region or the base of the gland both on the ipsilateral and the contralateral sides. We did not find predictors of CEPE. This may be due to the low incidence of CEPE in our cohort. While some studies have investigated predicting factors of $\mathrm{PSM}^{7}$ and $\mathrm{EPE}, 5,6$ few have specifically reported predictors of cEPE in unilateral prostate cancer. Such findings could help anticipate contralateral extension and help identify patients suitable for more aggressive contralateral nerve sparing.

Lastly, our results show that the nerve-sparing methods yielded similar rates of PSM when associated with ipsilateral and contralateral prostate cancer. We did not find a significant increase in PSM with more aggressive nerve-sparing techniques. Surprisingly, IF-NS resulted in less PSM than the less aggressive methods on the contralateral side. In our cohort, a lower percentage of cancer in biopsy material, a younger age, and a smaller prostate are independent predictors of IF-NS. Conversely, some studies show that age $>60$ and a prostate size $>60 \mathrm{~g}$ protect against PSM. ${ }^{7,24}$ Therefore, a lower percentage of cancer in biopsy material seems to be the only 
independent factor to explain favourably our results. Patient criteria used to perform aggressive nerve sparing were surgeon-dependent and may consequently not be identified by the multivariate model. Another explanation for our results is the fact the biggest proportion of PSM is localized at the apex, where little maneuver variation is possible ${ }^{25}$ and the use of nerve sparing is limited. This may contribute to why more aggressive nerve sparing did not result in more PSM.

Our study was not devoid of limitations. The low incidence of cEPE and CPSM may have limited the statistical ability to detect significant differences. Additionally, as multiple surgeons from multiple institutions participated in this study, the lack of central pathology may induce an interobserver bias in reporting EPE and PSM. Nonetheless, it did allow for a larger and more diverse cohort, which we feel makes the study more generalizable.

\section{Conclusion}

Aggressive contralateral nerve sparing on patients with unilateral disease on preoperative biopsy is attractive, but the risk of contralateral disease is high. However, cPCa is at a lower risk of EPE than disease on the ipsilateral side and, although not insignificant, the overall incidence of cEPE and cPSM is low. We found that a positive biopsy at the apex predicts CPCa and a higher proportion of PSM. This could be used as a red-flag to exert additional care during the dissection of the apex. This study suggests that aggressive contralateral nerve sparing does not increase the risk of PSM if performed with caution based on preoperative risk factors and intra-operative surgical judgement.

Competing interests: Dr. Bienz, Dr. Hueber, Dr. Trudeau, Dr. Alenizi, Dr. Valdivieso, Dr. Alom, Dr. Balbay, Dr. Canda, Dr. Mouraviev, Dr. Albala, Dr. El-Hakim, and Dr. Trinh and Dr. Latour declare no competing financial or personal interests. Dr. Saad is a member of the advisory boards for Amgen, Astellas, Janssen, Abbott, Sanofi and Bayer. He has also received research grants and honoraria from Amgen, Astellas, Janssen, Abbott, Sanofi and Bayer. He has participated in clinical trials in the past 2 years for Amgen, Astellas, Janssen, Sanofi, and Bayer. Dr. Zorn is an advisor, speaker, and proctor for Greenlight laser surgery from AMS. Dr. Trinh received honorarium from Intuitive Surgical in the past.

This paper has been peer-reviewed.

\section{References}

1. Tanya Navaneelan TJ. Le cancer au Canada : cancers du poumon, du côlon et du rectum, du sein et de la prostate2011. www.statcan.gc.ca. Accessed July 2, 2015.

2. Ficarra V, Novara G, Rosen RC, et al. Systematic review and meta-analysis of studies reporting urinary continence recovery after robot-assisted radical prostatectomy. Eur Urol 2012;62:405-17. http://dx.doi. org/10.1016/i.eururo.2012.05.045

3. Ficarra V, Novara $G$, Ahlering TE, et al. Systematic review and meta-analysis of studies reporting potency rates after robot-assisted radical prostatectomy. Eur Urol 2012;62:418-30. http://dx.doi. org/10.1016/i.eururo.2012.05.046
4. Novara G, Ficarra V, Mocellin S, et al. Systematic review and meta-analysis of studies reporting oncologic outcome after robot-assisted radical prostatectomy. Eur Urol 2012;62:382-404. http://dx.doi. org/10.1016/j.eururo.2012.05.047

5. Ohori M, Kattan MW, Koh H, et al. Predicting the presence and side of extracapsular extension: A nomogram for staging prostate cancer. J Urol 2004;171:1844-9; discussion 1849.

6. Graefen $M$, Haese A, Pichlmeier $U$, et al. A validated strategy for side specific prediction of organ confined prostate cancer: A tool to select for nerve sparing radical prostatectomy. J Urol 2001;165:857-63. http:// dx.doi.org/10.1016/S0022-5347(05)66544-5

7. Secin FP, Serio A, Bianco FJ Jr, et al. Preoperative and intraoperative risk factors for side-specific positive surgical margins in laparoscopic radical prostatectomy for prostate cancer. Eur Urol 2007;51:764-71. http://dx.doi.org/10.1016/i.eururo.2006.10.058

8. Kan RW, Kan CF, Ho LY, et al. Pre-operative tumor localization and evaluation of extra-capsular extension of prostate cancer: How misleading can it be? Urology 2014;11:1615-9.

9. Miano R, De Nunzio C, Kim FJ, et al. Transperineal versus transrectal prostate biopsy for predicting the final laterality of prostate cancer: are they reliable enough to select patients for focal therapy? Results from a multicenter international study. Int Braz J Urol 2014;40:16-22.

10. Sfoungaristos $S$, Perimenis P. Parameters predicting postoperative unilateral disease in patients with unilateral prostate cancer in diagnostic biopsy: A rationale for selecting hemiablative focal therapy candidates. Can Urol Assoc J 2013;7:E82-7.

11. Zorn KC, Widmer H, Lattouf JB, et al. Novel method of knotless vesicourethral anastomosis during robot-assisted radical prostatectomy: Feasibility study and early outcomes in 30 patients using the interlocked barbed unidirectional V-LOC180 suture. Can Urol Assoc J 2011;5:188-94. http://dx.doi.org/10.5489/cuaj.10194

12. Valdivieso RF, Hueber PA, Zorn KC. Robot assisted radical prostatectomy: How I do it. Part l: Patient preparation and positioning. Can J Urol 2013;20:6957-61.

13. Valdivieso RF, Hueber PA, Zorn KC. Robot assisted radical prostatectomy: How I do it. Part II: Surgical technique. Can J Urol 2013;20:7073-8.

14. Humphrey PA. Complete histologic serial sectioning of a prostate gland with adenocarcinoma. Am I Surg Pathol 1993;17:468-72. http://dx.doi.org/10.1097/00000478-199305000-00005

15. Shikanov S, Woo J, Al-Ahmadie $\mathrm{H}$, et al. Extrafascial versus interfascial nerve-sparing technique for robotic-assisted laparoscopic prostatectomy: Comparison of functional outcomes and positive surgical margins characteristics. Urology 2009;74:611-6. http://dx.doi.org/10.1016/i.urology.2009.01.092

16. Fontenot PA, Mansour AM. Reporting positive surgical margins after radical prostatectomy: Time for standardization. BJU Int 2013;111:E290-9. http://dx.doi.org/10.1111/i.1464-410X.2012.11640.x

17. Johnson MT, Ramsey ML, Ebel JJ, et al. Do robotic prostatectomy positive surgical margins occur in the same location as extraprostatic extension? World J Urol 2014;32:761-7. http://dx.doi.org/10.1007/ s00345-013-1149-5

18. Srivastava $\mathrm{A}$, Chopra $\mathrm{S}$, Pham $\mathrm{A}$, et al. Effect of a risk-stratified grade of nerve-sparing technique on early return of continence after robot-assisted laparoscopic radical prostatectomy. Eur Urol 2013;63:438-445.

19. Frota R, Stein RJ, Turna B, et al. Are prostate needle biopsies predictive of the laterality of significant cancer and positive surgical margins? BJU Int 2009;104:1599-603. http://dx.doi.org/10.1111/j.1464410X.2009.08648.x

20. Gallina A, Maccagnano C, Suardi N, et al. Unilateral positive biopsies in low risk prostate cancer patients diagnosed with extended transrectal ultrasound-guided biopsy schemes do not predict unilateral prostate cancer at radical prostatectomy. BJU Int 2012;110:E64-8. http://dx.doi.org/10.1111/i.1464410X.2011.10762.x

21. Smith JA Jr, Chan RC, Chang SS, et al. A comparison of the incidence and location of positive surgical margins in robotic assisted laparoscopic radical prostatectomy and open retropubic radical prostatectomy. J Urol 2007;178:2385-9; discussion 2389-90. http://dx.doi.org/10.1016/i.juro.2007.08.008

22. Tewari AK, Srivastava A, Mudaliar K, et al. Anatomical retro-apical technique of synchronous (posterior and anterior) urethral transection: A novel approach for ameliorating apical margin positivity during robotic radical prostatectomy. BJU Int 2010;106:1364-73. http://dx.doi.org/10.1111/i.1464410X.2010.09318.x

23. Kwak KW, Lee HM, Choi HY. Impact of capsular incision on biochemical recurrence after radical perineal prostatectomy. Prostate Cancer Prostatic Dis 2010;13:28-33. http://dx.doi.org/10.1038/ pcan.2009.19

24. Lallas CD, Fashola Y, Den RB, et al. Predictors of positive surgical margins after radical prostatectomy at a single institution: Preoperative and pathologic factors, and the impact of surgeon variability and technique on incidence and location. Can I Urol 2014;21:7479-86.

25. Tewari A, Peabody J0, Fischer $M$, et al. An operative and anatomic study to help in nerve sparing during laparoscopic and robotic radical prostatectomy. Eur Urol 2003;43:444-54.

Correspondence: Dr. Kevin C. Zorn, Director of Robotic Surgery, Assistant Professor of Urology, Minimally Invasive Urological-Oncologist, University of Montreal Hospital Center (CHUM) - Hôpital St. Luc, 1058 St-Denis St, Montreal, QC H2X 3J4; zorn.chumurology@gmail.com 